\title{
Um violoncelo todo seu: diálogos interartes em Guilhermina, de Mário Cláudio
}

\section{A cello of one's own: interartistic dialogues in Guilhermina, by Mário Claudio}

Jorge Valentim

Universidade Federal de São Carlos, São Carlos, São Paulo / Brasil jvvalentim@gmail.com

Resumo: O presente ensaio tem como objetivo propor uma leitura do romance Guilhermina (1985), de Mário Cláudio, sublinhando o diálogo estabelecido entre ficção e música, na recuperação biográfica da violoncelista portuguesa. Pretendemos mostrar que, para além de citações de cunho artístico e histórico, as referências às obras executadas por Guilhermina Suggia podem sugerir um possível caminho para a reflexão sobre os instrumentos de construção estrutural e discursiva do autor. Também objetivamos destacar as singularidades deste texto (o segundo a compor a Trilogia da mão), a partir das imagens selecionadas por Mário Cláudio da artista portuense e das atenções dadas ao seu repertório.

Palavras-chave: diálogos interartes; música; ficção portuguesa contemporânea; Mário Cláudio.

Abstract: The present essay aims to propose a reading of the novel Guilhermina (1985), by Mario Claudio, underlining the dialogue established between fiction and music, in the biographical recovery of the Portuguese cellist. We want to show that, in addition to references of an artistic and historical nature, the references to works performed by Guilhermina Suggia may suggest a possible way for reflection on the author's structural and discursive construction tools. We also aim to 
highlight the singularities of this text (the second to compose the Trilogia da mão), based on the images selected by Mário Cláudio of the artist from Porto and the attention given to his repertoire.

Keywords: interartistic dialogues; music; contemporary Portuguese fiction; Mário Cláudio.

Recebido em 11 de maio de 2018

Aprovado em 11 de julho de 2018

\begin{abstract}
Este texto é para Maria Thereza Abelha, que, num curso em 1992 (e lá se vão mais de 25 anos!), pintou, tocou e criou uma Trilogia da mão para alunos ouvintes boquiabertos, porque percebemos que estávamos também diante de uma Diva.

$[\ldots]$ eu nunca escrevo um romance que seja apenas um romance.

Todo o texto é construído de acordo com um padrão, um ritmo, que foi pensado propositadamente [...].

MÁRIO CLÁUDIO. 30 anos de trabalho literário.
\end{abstract}

Guilhermina não é uma mulher de beleza canónica mas é, sem dúvida, uma mulher perigosa. De refinadíssima sensibilidade e vibrante inteligência, é certamente uma mulher de exceção.

FÁTIMA POMBO. Guilhermina Suggia ou o violoncelo luxuriante.

Falar de diálogos possíveis entre literatura e música a partir de obras de escritores da contemporaneidade exige do seu leitor não apenas sensibilidade no trato do texto literário, mas também sutileza em perceber as nuances que certas inferências musicais convocam no momento de sua apropriação. Não será gratuito, portanto, iniciar a minha proposta de leitura com a fala do autor em foco, Mário Cláudio, quando chama a atenção para a peculiaridade com que trata a matéria efabulatória no seu projeto de composição romanesca.

Olhar para o romance como um constructo que tece teias dialogantes com outras áreas do saber e com discursos artísticos variados, 
obedecendo um padrão e um ritmo particulares que fogem da gratuidade ou da ingenuidade criadoras, parece ser realmente uma marca do autor da Trilogia da mão. Gosto mesmo de pensar que todo este repertório, que envolve desde uma tradição literária até revisitações do mundo das artes, por exemplo, pode ser compreendido dentro de um campo amplo de escolhas, apontando para uma constelação sua, muito particular, de referências culturais, que, para além de poetas, ficcionistas, filósofos e ensaístas, integrariam também os universos das artes plásticas e musicais.

Se os três artistas da mão, recuperados pela sua conhecida Trilogia (o pintor Amadeo de Souza-Cardoso, a violoncelista Guilhermina Suggia e a artesã Rosa Ramalha), proporcionam este tipo de reflexão, não menos os casos sintomáticos de António Nobre (Noites de Anto, 1988; Fotobiografia de António Nobre, 2007), Fernando Pessoa/Bernardo Soares (Boa noite, Senhor Soares, 2008), Leonardo da Vinci (Retrato de rapaz, 2014) e Lewis Caroll (O fotógrafo e a rapariga, 2015), revisitados pelo bordado ficcional de Mario Claudio, põem em claro aquela marca inconfundível do autor como um "escritor de plasticidade da língua, de diversidade de discursos e de pluralidade de temas, sem possibilidade de negar o seu arejamento" (MATOS, 2004, p. 35).

Todas estas invocações, que não deixariam de povoar os tecidos da escrita sob os auspícios de uma práxis intertextual, bem poderiam ser apreendidas, a partir daquele fenômeno da "multiplicidade", defendido por Ítalo Calvino (1990), como uma das marcas desta literatura portuguesa produzida também em fins de um milênio e início de outro.

Segundo o ensaísta italiano, a multiplicidade constitui a singularidade do "romance contemporâneo como enciclopédia, como método de conhecimento, e principalmente como rede de conexões entre os fatos, entre as pessoas, entre as coisas no mundo" (CALVINO, 1990, p. 121), propiciando assim uma gama de laços interdisciplinares entre textos, obras e autores dos mais diversos campos e das mais variadas áreas do saber. Na linha de raciocínio estabelecida por Calvino, portanto, a arte literária da virada do milênio estaria sujeita a uma proposta ambiciosa de amplitude de domínios, qual seja, a de "representar a multiplicidade das relações, em ato e potencialidade" (CALVINO, 1990, p. 127).

Pensando nesta potencialidade de representar, a partir das possibilidades dialógicas entre os discursos musical e literário, fico a me interrogar, se este não será um caminho possível para a leitura de certos títulos da ficção portuguesa do final do século XX, deixando em evidência 
as riquezas criadoras que tal multiplicidade pode proporcionar? Assim, sem hierarquizar o contexto e o gênero da obra convocada em graus de importância, podemos pensar, na esteira das idéias de Mário Claudio, que um romance tende, certamente, a ser produzido a partir de um intenso jogo intertextual, com um ritmo e um padrão pensados intencionalmente.

Quando se trata de analisar o texto literário, através de conhecimentos artísticos específicos, como a leitura aqui proposta se identifica, ou seja, de efetuar uma investigação dialógica a partir dos estudos literários e musicais, há dois caminhos possíveis para a percepção desta aproximação comparativa (OLIVEIRA, 2002). Um primeiro, de plano horizontal, quando há referências e alusões de termos, compositores e obras musicais no título e no conteúdo textuais; e um segundo, de plano vertical, quando há a apropriação e o uso (intuitivo ou deliberado) de técnicas comuns de estruturação e composição musicais na concepção e criação textuais. A partir deste intercâmbio, os discursos literário e musical, mesmo autônomos e independentes, não estão isentos de laços de irmandade que podem ser cada vez mais estreitos, ampliando assim, as suas possibilidades de leitura.

Munido deste raciocínio, atrevo-me, aqui, a propor uma leitura do romance Guilhermina (1986), de Mário Cláudio, procurando observar estas duas incidências: uma horizontal, em que citações de obras musicais do repertório violoncelístico, bem como de artistas e musicistas, contribuem para a construção da personagem biografada; e outra, vertical, em que, de maneira muito sutil e particular, o autor revisita determinadas formas musicais e com elas dialoga na composição da arquitetura 0 romanesca.

Inicio, portanto, pelo princípio: pelo conhecido quadro do pintor galês Augustus John, de Guilhermina Suggia, na sobrecapa da edição da Imprensa Nacional - Casa da Moeda. Ao contrário dos dois romances que compõem a Trilogia da mão (Amadeo, 1984, e Rosa, 1988), a imagem frontal não privilegia a obra dos seus criadores, transformados em protagonistas dos romances, mas expõe o próprio sujeito biografado. Em Guilhermina, é a própria violoncelista que surge pela obra plástica reproduzida na capa, no ato de uma performance com o instrumento que a consagrou no meio musical. Aqui, a escolha por esta imagem, especificamente, não me parece um gesto fortuito, quando outras poderiam ser escolhidas (as de António Carreiro e Amadeo de SouzaCardoso, por exemplo). Antes mesmo de o leitor folhear as páginas da 
narrativa marioclaudiana, ele depara-se com o corpo de uma mulher que se aglutina e se confunde com o do violoncelo que sobre o seu corpo se apoia. Na parte superior, a voluta e as cravelhas confundem-se com o emaranhado dos cabelos de Guilhermina, que parecem se expandir para o espelho e o estandarte do instrumento. A brancura dos seus braços sugere uma espécie de prolongamento pela alvura da crina do arco. E, por fim, a caixa de ressonância amadeirada do instrumento quase que se gruda e se funde ao corpo feminino, talhado por um longo vestido vermelho.

Este viés de leitura também seria confirmado por João Soares Santos, quando, em 1993 (ou seja, sete anos após a publicação da obra de Mário Cláudio), ao assinar o prefácio da biografia de Guilhermina Suggia, escrita por Fátima Pombo, reitera a organicidade e a sensualidade do corpo da violoncelista, aglutinadas nos exercícios performáticos da artista portuense. Segundo ele,

Nas versões expansivas de Guilhermina Suggia, as partituras convertidas em música tornam-se uma segunda criação. O seu corpo transmite acusticidade, os seus gestos são um tópico visual de escuta. $\mathrm{O}$ corpo que executa é a argila prévia do som. $\mathrm{O}$ "primum movens" da música é a carne. Precedendo-a, existe uma latência cutânea, somática. "Corpus" e "opus" estão em interpermuta. Para além da versatilidade no repertório, a natureza física e compenetrada das interpretações de Guilhermina absorvia a concepção prévia da obra. Do seu violoncelo a obra renascia e, enlaçando-nos com o seu dom, tocando maravilhosamente, ela encarnava aquilo que analogicamente Schopenhauer afirmou ser a música: "a imagem da vontade pura". Se a música proporciona um tempo paralelo de manifestação do lado recôndito da personalidade, se evoca o imponderável, conjura as propensões inatas, no sopro de deslumbramento que efere do talento de Guilhermina, no seu poder cativador, reside não apenas um nível amplo de exigência como também a melancolia de quem está só (SANTOS, 1993, p. 11-12).

A par de certas expressões com uma tonalidade excessivamente laudatória sobre a violoncelista portuguesa, não se poderá negar que o prefaciador pondera de forma muito pontual sobre a genialidade singular da artista, sublinhando de um lado a sua capacidade artística arrebatadora e, de outro, o seu poder de sedução visual, sugerindo, ao mesmo tempo, uma atenção sobre o seu caráter solitário. Se o músico solista experimenta 
uma sensação distinta da do camerista, porque executa um repertório que só depende de si, dos seus esforços e de sua subjetividade interpretativa (e não partilha com outros intérpretes, tal como ocorre na música de câmera), o isolamento e a solidão podem ser compreendidos como condições sine qua non para o sucesso de um intérprete de renome internacional.

Interessante observar que os atributos acústicos, acima mencionados por João Soares Santos, não deixam de surgir na plasticidade do quadro de Augustus John, acentuando os gestos da violoncelista como um "tópico visual de escuta" (SANTOS, 1993, p. 11). E estes, por sua vez, ressurgem sancionados pelo olhar meticuloso do narrador ao recuperar a trajetória da violoncelista:

Esta, pois, é a primeira representação com a qual o leitor se depara ao tomar posse da obra: a de uma Guilhermina numa pose sugestiva e sensual de performance em concerto.

$E$, ainda que esta imagem em muita se diferencie daquela descrita nas primeiras linhas do romance ("[...] Guilhermina, que com pouco mais de seis anos vai hoje a baptizar"; CLAUDIO, 1986, p. 11), é o próprio narrador quem possibilita esta leitura da existência da protagonista atrelada ao seu instrumento musical:

Estremeciam as vidraças, os cabelos ficavam riços de Guilhermina, o corpo do Mundo sentindo na caixa que ao corpo encostava. [...] Era a aventura primeira, conjugada com o mar estendido para além, aos bichos se misturando que nele se viam, manuseado tesouro por certa sereia que detinha o abre-te-Sésamo do reino submerso, longamente cantava entre um luxo de algas. E o instrumento se calava, susceptível todavia de despertar a um impulso, companheiro da taça-de-pé onde os pêssegos amadureciam. $\mathrm{O}$ arco se aquietava que o vinha tocar, retendo em seu descanso encantamentos e maldições, inconsciente de tanto que sabia. Desgrenhava o vento a corrida pelo jardim, uma rã sobrevivia no espelho-de-água, de inútil amor coaxando sem tréguas. Meditaria Guilhermina no percurso das nuvens, suas formas e tintas, as figuras que levam, aladas e semi-nuas, seus ceptros e tridentes, seus escudos e cítaras? E o violoncelo, que passos conheceria do discurso dos dias, que astúcias e que vitórias? (CLAUDIO, 1986, p. 13-14).

Elevado quase ao estatuto de personagem, o violoncelo recebe nomes personificadores de acordo com os gestos, o espírito e a execução 
da violoncelista. Já na sua infância, ela é marcada por uma metamorfose no contato livresco, graças à aproximação e à intimidade com o instrumento musical. Das obras fantásticas de contos de fadas, tão comuns no elenco das crianças de sua idade, Guilhermina cedo se depara com outros tipos de publicação e com leituras de diferentes signos:

\begin{abstract}
Alguns romances a enfeitiçam, ainda, de cavaleiros e anões, mas outro é já o livro que lhe colocam diante esses anjos suspeitados, terríveis de fascínio que para ficar a visitam. Luís se chama, Constantino ou Viriato, ao sabor dos instantes e do aroma que têm. Aprende Guilhermina, hesita, percebendo que a transportam, o cais ignora aonde irá desembarcar (CLAUDIO, 1986, p. 15).
\end{abstract}

Como bem atesta o narrador, é, portanto, a partir do contato visual e sensível de Guilhermina com a leitura musical das partituras e do contato táctil com o violoncelo colado à sua epiderme, ganhando novos nomes e reagentes às suas interpretações, que ambos (mulher e violoncelo) engendram uma espécie de simbiose que só no espaço da arte a existência deles ganharia plenitude: " $E$ no violoncelo identifica a metamorfose da voz entre meninice e mocidade, que a certos caracteriza dos que à sua volta vê" (CLAUDIO, 1986, p. 21).

Assim, observando a união de ambos na arte performática, a trajetória da violoncelista vai sendo deslindada passo a passo, de forma temporalmente organizada, deixando sempre em evidência o exercício de realização artística da musicista portuense. Aqui, seguindo os passos de uma leitura horizontal do texto, os principais títulos do repertório executado por Guilhermina aparecem ricamente mencionados nos diversos palcos por onde pisou: (1) em 1896, no Palácio de Cristal, a Fantasie elegante sur "L'etoile du nord", de Meyerbeer, op. 74, de Sebastien Lee, e no Clube de Leça, Arlequin et papillons, op. 3 no. 1, de David Popper (CLAUDIO, 1986, p. 19-20); (2) em 1901, no Salão do Laranjal, a Sonata em lá menor, op. 36, de Edward Grieg; (3) já em Paris, a partir de 1907, as Suites para Violoncelo, de Johann Sebastian Bach, disputadas com Pablo Casals, seu companheiro ("Entre as seis suítes, de apenas duas, a em sol e a em dó, haveria de se apoderar como de coisa sua"; CLAUDIO, 1986, p. 39), e o Concerto Duplo para violoncelos em Ré Maior, op. 69, de Emmanuel Moór; (4) a partir de 1915, em Londres, o Concerto para Violoncelo em mi menor, op. 85, de Edward Elgar, as peças Sicilienne e Après un rêve, de Gabriel Fauré, e o Concerto no. 2 
para Violoncelo em Ré Maior, de Joseph Haydn, cujo $3^{\circ}$ movimento, o Rondó, "andarilho e folgazão, que a possui" (CLAUDIO, 1986, p. 65), colocaria Guilhermina Suggia definitivamente entre os ícones das referências fonográficas; (5) a partir de 1924, já de retorno a Portugal, executa com sucesso retumbante, no Porto e em Lisboa, o Concerto para violoncelo em ré menor, de Édouard Lalo, e, num sarau particular em sua casa, a Suite no. 1 para violoncelo, de J. S. Bach; (6) em tempos pós-Segunda Guerra Mundial, executa, sob a batuta de Sir Malcolm Sargent, o Concerto para violoncelo em si menor, op. 104, de Antonin Dvorak, além de nova performance do Concerto de Elgar, o Concerto para violoncelo em Dó Maior, op. 20, de Eugen d'Albert, e, em sua última apresentação, a virtuosística Sonata para violoncelo e piano no. 1, em dó menor, op. 32, de Camille Saint-Sãens.

O que se depreende de todo este cuidado em enumerar os pontos fortes de execução da artista é a sua capacidade de circular entre os principais títulos do repertório violoncelístico com um "à vontade" que a coloca definitivamente entre as grandes intérpretes do século XX. Inseridos, no entanto, dentro da narrativa, estas referências tem uma estratégia de construção significativa. Por isso, concordamos com Dalva Calvão, quando sublinha todo este repertório como uma forma perspicaz de Mário Cláudio assinalar a "trajetória da artista, contribuindo para a certeza histórica dos fatos relatados e conferindo concretude à biografia composta, ao explicitar para o leitor o inquestionável e real espaço de realização artística da violoncelista" (CALVÃO, 2008, p. 123). Mas, para além das motivações estratégicas, gosto de pensar, na esteira das afirmações do autor, que, se um romance é mais que um romance, se nele existe um ritmo e um padrão propositais, então, o bordado narrativo de Guilhermina não será uma exceção.

Recorro, aqui, a Ana Paula Arnaut, que, na sua análise de Amadeo, sublinha a apropriação intertextual no projeto criador de Mário Cláudio, verificando que "a técnica de registo escrito-narrativo especula a própria técnica pictórica-figurativa do pintor modernista" (ARNAUT, 2005, p. 37). Em outras palavras, a ensaísta portuguesa destaca a capacidade do autor da Trilogia da mão, em copiar lato sensu os planos do artista plástico, "numa escrita biograficamente ziguezagueante onde se articulam os passos do biografado e dos biografantes" (ARNAUT, 2005, p. 37).

Se, realmente, no romance de abertura da Trilogia, este processo de apropriação faz-se presente, em Guilhermina, o mesmo também 
ocorre. No entanto, no lugar de uma absorção de técnicas de construção pictórica, atrevo-me a pensar que, neste texto, Mario Cláudio, de maneira intencional, apodera-se de certos recursos composicionais. É, aliás, o próprio narrador que convida a uma leitura vertical de absorção de elementos estruturais:

Para si só reservara a Suite no. 1, logo no prelúdio o carácter imprimira da obra total. Executara uma allemande cantada, muito melódica, pelo minuete corta, agora, na mesmérica basílica de arco-íris, o primeiro maior, mais estático o segundo, o terceiro, por fim, de bíblico aparato (CLAUDIO, 1986, p. 105).

Ora, se observamos com atenção, a peça indicada para uma execução exclusiva da violoncelista não gratuitamente é a Suite de Bach, forma musical barroca composta de "uma reunião, formando um todo, de diversas peças instrumentais independentes entre si, porém combinadas para serem executadas de maneira seguida" (ZAMACOIS, 1982, p. 151). Neste sentido, fico a me interrogar se, aquela "estética do fragmento" (CALVÃO, 2008, p. 144), designada por Dalva Calvão, enquanto recurso desestabilizador da sequencia monolítica do enredo narrativo, facilmente encontrada nos romances da Trilogia da mão, não poderia ser pensada, a partir de um padrão e de um ritmo articulados propositadamente, em diálogo com a composição musical? Entendidos como pequenos eixos sequenciais da trajetória de Guilhermina, pequenos flashes da sua vida cotidiana, pequenos retratos dos preparativos e dos seus ensaios privados, não se poderá entender, enfim, estes pequenos fragmentos, que compõem a tessitura narrativa de Guilhermina, como peças autônomas e independentes de uma grande suíte romanesca composta pelo escritor português? Não serão estes pequenos blocos narrativos uma espécie mesmo de peças combinadas em sequência na recuperação ficcional da violoncelista portuguesa?

Interessante observar que, ao contrário de Amadeo e Rosa, as imagens fotográficas não são distribuídas em dois blocos ao longo da narrativa, mas em apenas um, e propositalmente localizado no centro da edição em livro. Deste modo, a exemplo de uma forma musical triádica, não se poderá pensar a arquitetura de Guilhermina como uma narrativa em três movimentos, como aquela enunciada pelo narrador? A primeira (“o carácter imprimira da obra total"; CLAUDIO, 1986, p. 105), se não textualmente maior, com certeza aquela que concentra uma importância 
fundamental na formação da artista, envolvendo o período de sua iniciação musical até à vida em Paris e à separação de Pablo Casals. A segunda, mais estática, composta pelas fotografias, imagens congeladas que tentam recompor sem palavras e sem sons a sua vida. E, por fim, a terceira, de "bíblico aparato" (CLAUDIO, 1986, p. 105), evidenciando a autonomia e a consolidação de Guilhermina como uma prima donna do violoncelo, sem laços de dependência com qualquer artista ou mentor. Mas, a mulher e a musicista na sua pujança total.

Interessante observar que, para além desta arquitetura triádica percebida na distribuição da materialidade literária da obra (narrativa - imagens fotográficas - narrativa), as fotografias reunidas no interior do corpo textual obedecem, de certo modo, a sequencia do fio narrativo estabelecido pela mão autoral. Da Guilhermina, filha de Augusto e Elisa Suggia e irmã de Virginia, com quem inicia a sua vida musical (CLAUDIO, 1986, p. 49-51), o leitor é paulatinamente guiado à Guilhermina camerista (CLAUDIO, 1986, p. 52), à Guilhermina mulher de Pablo Casals (CLAUDIO, 1986, p. 53-55), à violoncelista e mulher madura e buscando sua independência (CLAUDIO, 1986, p. 54 e 56), à apreciadora de animais em cenas domésticas (CLAUDIO, 1986, p. 5758), à mulher portuguesa de volta à terra e casada com o médico José Carteado Mena (CLAUDIO, 1986, p. 59), à solista consagrada sob a batuta de maestros reconhecidos (CLAUDIO, 1986, p. 60), e, por fim, à Guilhermina devotada e casada com o seu instrumento: o violoncelo (CLAUDIO, 1986, p. 61-64). Assim, nesta última parte das imagens ("Uma vida"), são muitas as Guilherminas representadas. Para além daquelas que os desenhos e os quadros de Amadeo de Souza-Cardoso, António Carreiro e Augustus John legaram, há as deixadas por diferentes ângulos fotográficos, sugerindo quase uma necessidade imperiosa do autor em suprir num abundante e rico acervo de imagens aquilo que a gravação audiovisual não foi capaz de captar.

Um detalhe importante e que passa quase desapercebido ao leitor é o fato de que toda esta seção central, formada por imagens, desenhos, quadros e fotografias, fazem parte do texto e não se trata de um apêndice anexado no interior da obra. Prova disto é que, apesar de os números das páginas não aparecerem no rodapé central, estas são computadas e contadas como tais. Assim, entre as páginas 49 e 64, há uma espécie de silenciamento da voz narrativa para o surgimento imagético de uma composição complementar ao narrado. Por isso, a numeração 
interrompida na página 48 reaparece retomada na página 65 . Não se iluda o leitor, achando que tal informação seja gratuita, posto que, com esta contagem, afirma-se categoricamente que todo o bloco central constitui uma parte integrante da obra ficcional, devendo, portanto, ser como tal considerada na gramática narrativa de Guihermina.

Não me parece gratuito o fato de que o próprio narrador chega a dar pistas desta possível estrutura musical do romance, a partir do momento em que ele revela pistas bem sugestivas para esta leitura, afinal, quando ele encontra-se reunido com Álvaro e Priscila, a sua dúvida sobre as condições de feitura do texto em processo indica uma abertura para um diálogo interartes:

De sua biografia cada vez menos me institui seu tão certo secretário, como ainda não há muito, quando de Augusto, o velho pai, me fazia o recorte de boémio musicista, da estirpe desses que vão de terra em terra, rodopiando de casório em casório. [...] Ali estávamos, pois, practicando sobre o Gerez, Álvaro de cigarro esquecido entre os dedos, Priscila reclinada em suas almofadas. $\mathrm{Na}$ esperança ali estávamos de que progredisse o romance, a escrita se corporizasse, o andamento seguinte pudesse principiar (CLAUDIO, 1986, p. 43; grifos meus).

Interessante observar que, em meio a expressões articuladas específicas do universo de criação escritural e literária (o romance que se espera entrar numa fase de progresso e a escrita que tenta ganhar corpo), o narrador opta por uma última designação oriunda do discurso musical, sugerindo que, como numa peça sinfônica ou num concerto, por exemplo, o texto pudesse seguir uma sequência, sublinhando-a como o "andamento seguinte" (CLAUDIO, 1986, p. 43). E, vale lembrar, na esteira dos ensinamentos de Michel Brenet, que "andamento" é exatamente uma "espécie de progressão ou repetição de um passo dado com a mesma figuração de valores e com relações análogas de melodia ou de harmonia" (BRENET, 1976, p. 28). Ou seja, é o indicador temporal e rítmico dos diferentes movimentos de uma peça musical, moldando-lhe o caráter e proporcionando uma indicação direta ao intérprete. Neste sentido, gosto de pensar que, muito longe de uma gratuidade, esta proposição do narrador bem demonstra que a estrutura do romance em construção pode, sim, estabelecer diálogos com a própria arte da sua personagem, recriada pelas malhas da efabulação. 
Integrados, portanto, numa estrutura que aglutina quadros, retratos, desenhos, fotografias e efabulação biográfica, todos estes elementos ganham uma configuração enciclopédica, tal como aquela desenhada por Ítalo Calvino (1990), na medida em que procuram redesenhar e recompor uma artista marcada pela multiplicidade e dão ao romance Guilhermina essas mesmas características.

Mas, encerrar estas considerações sem ponderar, pelo menos, um aspecto sobre a trajetória da artista recriada nas malhas da ficção, poderia parecer uma incoerência, afinal, parodiando o conhecido ensaio de Virginia Woolf (2014), o título desta reflexão evoca exatamente aquilo que a protagonista suscita, quando encontra com seu instrumento musical, seja no espaço íntimo dos ensaios musicais, seja no público das performances de concerto e de música de câmera: a possibilidade de liberdade e de autonomia do sujeito feminino.

Ainda que a imagem recuperada e efabulada de Guilhermina pareça indicar a trajetória de uma mulher dependente dos sustentáculos masculinos e coincidente com a papel de subalternidade típico das primeiras décadas do século $\mathrm{XX}$, gosto de pensar que o narrador do romance de Mário Cláudio oferece um caminho completamente inverso dos lugares-comuns esperados. Basta observar, por exemplo, que, na seção central, as imagens e as fotografias iniciam com a presença paterna (Augusto de Medina Suggia) e demarcam os espaços conjugais da Guilhermina companheira e esposa (com Pablo Casals e José Casimiro Carteado Mena). Mas, as derradeiras figurações consolidam a Guilhermina artista e intérprete implacável nas suas apresentações. Seja nos palcos com a orquestra (sob a regência de Sir Malcolm Sargent), seja nos momentos de ensaio e performances solistas, das páginas 60 a 64, encontramos 8 imagens que revelam uma Guilhermina Suggia inseparável do violoncelo.

Neste sentido, proponho pensar se, numa justa evocação das inspirações de Virginia Woolf (2014), sobretudo aquelas pontuadas no seu ensaio "Um teto todo seu", não poderíamos entender que, através da música, a Guilhermina protagonista descobriu um violoncelo todo seu, ou seja, um instrumento singular de manifestação da sua arte, mas, também, e sobretudo, de sua autonomia e de sua liberdade como artista e como mulher. Aqui, acredito que Mário Cláudio presta uma belíssima homenagem à Guilhermina Suggia, autora de ensaios rigorosos e assertivos na defesa da interpretação do seu instrumento de eleição. Basta verificar o texto de abril de 1920, "The Violoncello", publicado na revista 
Music \& Letters, onde a musicista portuguesa defende vigorosamente a qualidade daqueles que se propõem a tocar o instrumento:

As sonatas para piano e violoncelo são música de câmara em absoluto e deveriam ser ensaiadas com tanto cuidado e exaustão como um quarteto de cordas, e até mais, dados os maiores problemas de equilíbrio. Se um pianista e um violoncelista decidissem tornar-se executantes de sonatas e ensaiassem e actuassem juntos durante anos, a questão do equilíbrio tornarse-ia então um mero incidente de interpretação. Presentemente é este problema, praticamente não resolvido, que transforma estas mesmas sonatas num fracasso. Cada uma das cinco sonatas de Beethoven é uma peça de arte completa e foi escrita por Beethoven de modo a ser um sucesso absoluto. Beethoven não cometeu nenhum erro. As partes de piano e as de violoncelo estão marcadas com o maior cuidado e de tal modo que, se fossem executadas como deveriam ser, rapidamente se encontrariam audiências e amantes de música por todo o lado, descobrindo novas pelas de Beethoven! (SUGGIA, 1920 apud POMBO, 1993, p. 384-386).

Com uma verve reflexiva preocupada com os caminhos interpretativos de seus contemporâneos, Guilhermina Suggia defende a qualidade e a sensibilidade na leitura, na execução e na interpretação de peças camerísticas, como as Sonatas para Violoncelo e Piano, de Beethoven, obras, aliás, que conhecia muito bem. Na verdade, se não havia um público interessado neste tipo de música, a violoncelista aponta a responsabilidade não sobre o compositor, mas sobre os executantes, que, na sua perspectiva, não desenvolviam um trabalho prévio de qualidade e de exaustão no preparo e na concepção artística das obras.

Tem razão Fátima Pombo, biógrafa da instrumentista portuguesa, quando frisa o caráter invulgar desta mulher e artista, afinal, "Guilhermina não é uma mulher de beleza canónica mas é, [...] certamente uma mulher de exceção" (POMBO, 1993, p. 24), seja nas suas apresentações, seja nas suas reflexões ensaísticas.

Da Guilhermina violoncelista, portanto, à Guilhermina, protagonista do romance de Mário Cláudio, o leitor depara-se com uma criatura ficcional múltipla nos contornos com que é representada. E tanto assim é que a última imagem desta artista não incide numa máscara mortuária, mas numa vida que, até os últimos instantes, não conseguiu se desapegar da música e do violoncelo. Por isso, ao leitor, é oferecido o trecho da Suite no. 1 de 
Bach, executada fantasmagoricamente por uma mulher moribunda, na cama, a dedilhar de memória a melodia da peça que "para si só reservara" (CLAUDIO, 1986, p. 105). Nos últimos instantes de vida, a protagonista parece conceder ao público leitor uma última performance, mais intimista e mais particular, porque presenteia-o com uma peça que para si tinha um significado afetivo e musical: "Na barra do lençol, esforçados, seis vezes os dedos se lhe moveram,

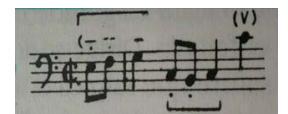

Eram os compassos de uma bourée de Bach, infinita alegria, da terra levantada para ser relâmpago, à treva recolhida, saciada" (CLAUDIO, 1986, p. 116).

É, portanto, esta Guilhermina, com um físico incomum, "nariguda e abrupta, com a angulosidade que deixa presumir uma pele resistente, um rompante em nas têmporas se depejar mancheias de água-de-colónia" (CLÁUDIO, 1986, p. 21), que invade e permanece num meio circundado por homens e dominado por uma ordem masculinista impiedosa, com a qual o autor parece simpatizar. É esta musicista de corpo concreto, que se torna parte sinestésica do próprio instrumento, o seu grande leitmotiv. A exemplo de Virginia Wolf, a artista portuguesa parece incitar a imaginação do leitor que, acompanhando os passos de uma mulher autônoma e independente, acredita estar diante de uma criatura que reivindica um violoncelo todo seu. Por isso, acredito que Guilhermina, o texto ficcional, jamais poderia ser encarado como "um romance que seja apenas um romance" (CLAUDIO, 1999, p. 21). Se "a literatura assume muitos saberes" (BARTHES, 1989, p. 18), como ensinou Roland Barthes, em sua magistral Aula, então, não será possível ler Guilhermina como um autêntico romance musical, que dialoga com formas e com técnicas de composição singulares, permitindo ao leitor a possibilidade de contato com outros universos e discursos artísticos?

Deixo de propósito esta pergunta no ar, mas com uma resposta de fácil conclusão diante das breves reflexões que aqui procurei tecer. Não posso concluir, no entanto, sem deixar uma outra interrogação, em forma de voto e de desejo pessoal: até quando os olhos do Prêmio Camões não se voltarão para o Norte e reconhecerão o legado singular de um escritor como Mario Claudio? Se um dia isto acontecer, aí sim, atrevo-me a afirmar que a sinfonia deixa de ser inacabada e ganha um digno e justo grand finale. Ou, parafraseando Virginia Wolf, o Prémio Camões ganhará um escritor todo seu. 


\section{Referências}

ARNAUT, Ana Paula. Amadeo(s). In: PETROV, Petar(Org.). O romance português pós-25 de abril. O Grande Prémio de Romance e Novela da APE (1982-2002). Porto: Roma Editora, 2005. p. 37-54.

BARTHES, Roland. Aula. Tradução e posfácio de Leyla Perrone-Moisés. São Paulo: Cultrix, 1989.

BRENET, Michel. Diccionario de la Música. Traducción de J. Ricart Matas, José Barberá Humbert e Aurelio Capmany. Barcelona: Editorial Iberia, 1976.

CALVÃO, Dalva. Narrativa biográfica e outras artes. Reflexões sobre escrita literária e criação estética na Trilogia da mão, de Mário Cláudio. Niterói: EdUFF, 2008.

CALVINO, Ítalo. Seis propostas para o próximo milênio. Tradução de Ivo Barroso. São Paulo: Companhia das Letras, 1990.

CLAUDIO, Mário. 30 anos de trabalho literário 1969-1999. Porto: Galeria da Árvore, Fundação Engenheiro António de Almeida, 1999.

CLAUDIO, Mário. Guilhermina. Lisboa: Imprensa Nacional - Casa da Moeda, 1986.

OLIVEIRA, Solange Ribeiro de. Literatura e música. Modulações póscoloniais. São Paulo: Perspectiva, 2002.

POMBO, Fátima. Guilhermina Suggia ou o violoncelo luxuriante. Porto: Fundação Engenheiro António de Almeida, 1993.

SANTOS, João Soares. Prefácio. In: POMBO, Fátima. Guilhermina Suggia ou o violoncelo luxuriante. Porto: Fundação Engenheiro António de Almeida, 1993. p. 9-12.

SUGGIA, Guilhermina. The Violoncello. In: POMBO, Fátima. Guilhermina Suggia ou o violoncelo luxuriante. Porto: Fundação Engenheiro António de Almeida, 1993. p. 374-387.

WOOLF, Virginia. Um teto todo seu. Tradução de Bia Nunes de Sousa. São Paulo: Tordesilhas, 2014.

ZAMACOIS, Joaquín. Curso de formas musicales. Barcelona: Editorial Labor, 1982. 